\title{
Influence of thread parameters on the withdrawal capacity of wood screws to optimize the thread geometry
}

\author{
Kevin Hoelz ${ }^{1}\left[\right.$ ] Philipp-Tobias Dörner ${ }^{1} \cdot$ Julian Hohlweg $^{1} \cdot$ Sven Matthiesen ${ }^{1}$
}

Received: 30 July 2021 / Accepted: 25 January 2022 / Published online: 14 February 2022

(c) The Author(s) 2022

\begin{abstract}
For wood screw connections, the withdrawal capacity is essential and is therefore an optimization target for wood screws. The withdrawal capacity is based on the composite action between the screw thread and the wood. Optimizing thread geometry requires knowledge of how thread parameters influence the withdrawal capacity. Up to now, this knowledge is largely unknown. Therefore, the objective is to determine the influence of thread height $(1 \mathrm{~mm} ; 1.48 \mathrm{~mm})$, flank distance $(3.04 \mathrm{~mm}$; $6.08 \mathrm{~mm})$, lead angle $\left(6.8^{\circ} ; 13.6^{\circ}\right)$, and thread angle $\left(30^{\circ} ; 55^{\circ}\right)$ on the withdrawal capacity. The influences are investigated for a tangential screw-in direction in spruce. For this, flat ribbed bars, so-called threaded test objects, are used. The effect on the withdrawal capacity is measured using an experimental setup based on test standard EN 1382 in two different planes of the flat thread to the wood fiber. 242 tests in RT plane and 286 in TL plane were analyzed with multifactorial analyses of variance. The thread height, flank distance, and thread angle show significant effects in both planes. A larger thread height, a smaller thread pitch, and a more acute thread angle increase the withdrawal capacity. Only in RT plane, a larger lead angle shows higher withdrawal capacity. The determined effects can be used to design the thread geometry of wood screws with higher withdrawal capacities. The accuracy of calculation models for the withdrawal capacity of wood screw connections can also be improved based on the findings. With the results, confirmation could be found for known models based on the theory of compression cones explaining the influences of the flank distance and thread angle.
\end{abstract}

\section{Introduction}

Wood screw connections use wood screws made of steel to join elements made of wood or wood-based materials, as well as metal-wood connections (Sydor 2019). Wood screw connections are characterized by a wide application potential and are very attractive from an economic perspective (Ballerini 2012). Most often, self-tapping wood screws are used. One of their advantages is their variable, non-standard screw geometry, which allows a high withdrawal capacity and installation without pre-drilling (Ringhofer et al. 2015b). Therefore, each manufacturer has wood screws with different specific geometric and material properties that differ from competitors (Pirnbacher und Schickhofer 2007). For use in load-bearing timber connections, self-tapping wood screws must fulfill the Construction Products Regulation (CPR) represented by CE marking based on EN 14592 (2012) or

Kevin Hoelz

kevin.hoelz@kit.edu

1 IPEK, Institute of Product Engineering, Karlsruhe Institute of Technology (KIT), Karlsruhe, Germany
European Technical Assessment (ETA). For this approval, the withdrawal capacity is required, which is determined in experimental tests. The test setup and the test procedure for determining the withdrawal capacity are defined in EN 1382 (2016). Therefore, the withdrawal capacity is an optimization target for the design of wood screw geometry.

The withdrawal capacity is based on the composite action between the screw thread and the wood and hence is defined by the wood properties and geometric parameters of the thread (Ringhofer et al. 2015b). Wood has a pronounced anisotropy due to its naturally grown structure. Anisotropy describes the direction dependence of the properties of wood (Höfferl et al. 2016). A distinction is made between the main directions longitudinal (L), radial (R), and tangential (T), which form a coordinate system (Franke und Quenneville 2011). The longitudinal direction corresponds to a screw-in angle of the wood screw of $0^{\circ}$ to the wood fiber. The planes resulting from these directions are RT, TL, and LR. In timber construction in Central Europe, fir and spruce are the most commonly used woods (Hoffmeyer 2016).

The influences of the screw connection on the withdrawal capacity are usually investigated from the point of view of the 
wood properties, but rarely from the point of view of the thread geometry (Sydor 2019). For the optimization of wood screw threads, knowledge of how the thread parameters influence the withdrawal capacity is necessary. The parameters of the wood screw thread are presented below. Their description is followed by a discussion of the studies that have investigated the influence of the thread parameters on the withdrawal capacity.

\subsection{Parameters of wood screw threads}

According to Sydor (2019), wood screws can be classified into five different elements: head, unthreaded shank, shank profile, threaded shank, and tip. The thread transmits the forces into the wood (Sydor 2019). Figure 1 shows the elements of wood screws and relevant thread parameters for single-start threads. The thread parameters can be described according to ISO 5408 (2009).

Relevant thread parameters are the thread height $a$, outer diameter $d$, inner diameter $d l$, lead $P$, lead angle $\varphi$, thread angle $\alpha$, and root depth $r$. The thread height is defined by the radial distance between the crest and root of a thread ridge (ISO 5408 2009). Thus, the thread height is half the difference between the outer diameter and the inner diameter. The lead is the axial displacement of a point following its helix at one turn. The lead angle $\varphi$ for threads depends on the lead $P$ and the outer diameter $d$ according to Eq. (1) (ISO 5408 2009).

$\varphi=\arctan \left(\frac{P}{\pi \cdot d}\right)$.

The flank distance is the axial distance between two immediately adjacent flanks, but is independent of the lead angle. For single-start threads of wood screws, the flank

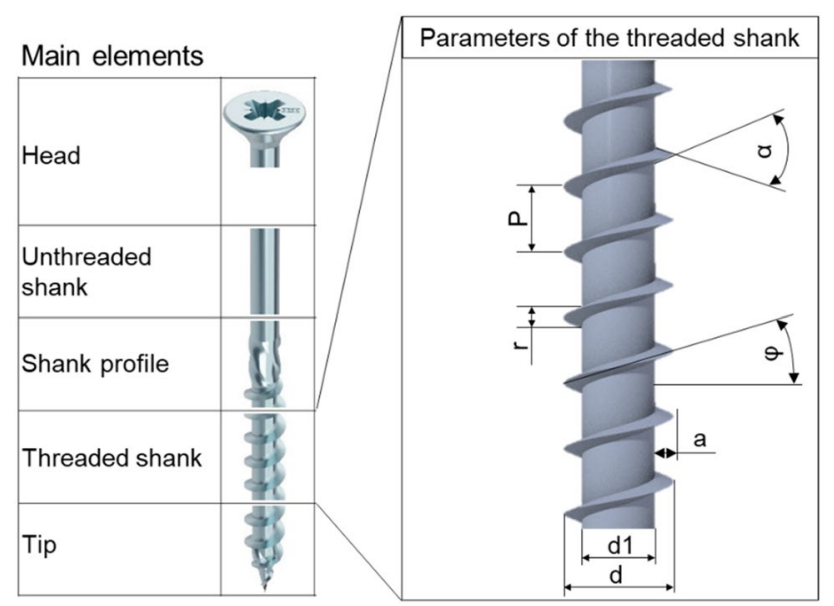

Fig. 1 On the left, elements of wood screws (Sydor 2019); on the right, parameters of the threaded shank (Hoelz et al. 2021c): thread height a, outer diameter $d$, inner diameter $d l$, lead respectively flank distance $P$, lead angle $\varphi$, thread angle $\alpha$, and root depth $r$ distance is equal to the lead. The thread angle is formed by two adjacent flanks in an axial plane (ISO 5408 2009). The root depth, or ridge thickness, is the axial distance between two adjacent flanks of a ridge (ISO 5408 2009). The root depth is geometrically dependent on the thread height and thread angle due to the fundamental triangle of the ridge.

\subsection{Influences of thread parameters on the withdrawal capacity}

The influence on the withdrawal capacity is described in different numerical models by Frese et al. (2010), Ringhofer et al. (2015b), Blaß et al. (2006), and Ringhofer et al. (2015a). The aim of these models is to calculate the withdrawal capacity of self-tapping wood screws for the design of screw connections independently from manufacturers. For this reason, an as general as possible formula with only few thread parameters is desired. The model by Frese et al. (2010) defined the effective screw-in length lef, the raw density of the wood $\rho k$, and the outer diameter $d$ of the wood screw as independent variables. For optimizing the geometry of wood screws, these parameters are not suitable because they are often specified by the application or dimensioning.

Gaunt (1997) investigated the influence of the thread geometry on the withdrawal capacity of six types of screws screwed into pine for a screw-in angle of $0^{\circ}$ to the wood fiber. The objective of the study was to determine relationships between lead, thread height, and root depth on the withdrawal capacity. Gaunt (1997) suspected a positive effect of a large ratio between thread height $a$ and root depth $r$ on the withdrawal capacity. However, no significant influence of the investigated thread geometry on the withdrawal capacity could be shown. The screw type with the largest thread height failed in the thread and could therefore not be investigated.

Pirnbacher und Schickhofer (2007) investigated the influence of the thread geometry on the withdrawal capacity using commercial self-tapping screws. For this purpose, screws with an outer diameter of $8 \mathrm{~mm}$ from different manufacturers were used. In addition to their thread parameters such as lead, thread height, inner diameter, or lead angle, these also differed in the geometry of the screw tip or the milling ribs. The investigation was carried out in spruce for screw-in angles of $0^{\circ}$ and $45^{\circ}$ and for a screw-in angle of $90^{\circ}$ in glued laminated timber. For an angle of $0^{\circ}$, no influence of the parameters on the withdrawal capacity could be shown. In contrast, an influence of the screw types on the withdrawal capacity was visible for $90^{\circ}$ to the wood fiber and at an angle of $45^{\circ}$. A difference of approx. $10 \%$ on the withdrawal capacity could be determined between the examined screws (Pirnbacher und Schickhofer 2007). However, it could not be shown which thread parameters cause this effect. 
In a study by Hübner (2014), the influence of the lead on the withdrawal capacity was investigated. For this purpose, commercial self-tapping wood screws with an outer diameter of $7.5 \mathrm{~mm}$ were used, which varied not only in lead but also in inner diameter, thread angle, and number of starts of the threads. The lead was statistically investigated with values of $2.6 \mathrm{~mm}$ (fine), $3.16 \mathrm{~mm}$ (medium), and $5.2 \mathrm{~mm}$ (coarse) using Welch's tests. The investigation was performed for a screw-in angle of $0^{\circ}$ as well as $90^{\circ}$ in both spruce and beech. For spruce, no influence of the lead could be shown for any screw-in angle. For beech, a significant influence can be shown for both screw-in angles only between fine and coarse lead as well as for a screw-in angle of $0^{\circ}$ between medium and coarse lead. Hübner (2014) concluded that only limited conclusions can be drawn from these differentiated results due to lack of significance.

The influence of the lead on the withdrawal capacity was also investigated by Sydor et al. (2016). Wood screws with an outer diameter of $7 \mathrm{~mm}$ were used. The lead was varied at factor levels of $2.5 \mathrm{~mm}, 3 \mathrm{~mm}$, and $3.5 \mathrm{~mm}$. These were investigated at a screw-in angle of $90^{\circ}$ in radial screw-in direction as well as in tangential screw-in direction in pine wood. The result of the investigation is that in radial screw-in direction, the lead of $3 \mathrm{~mm}$ achieved the highest withdrawal capacity. In the tangential screw-in direction, the highest withdrawal capacity was determined for the lead of $2.5 \mathrm{~mm}$. Sydor et al. (2016) concluded that for the radial screw-in direction, there is no strong correlation between lead and withdrawal capacity, while for the tangential screw-in direction, the withdrawal capacity decreases with increasing lead. No statistical tests were applied to prove this relationship. Comparing the test results by Sydor et al. (2016) with the results for softwood for a screw-in angle of $90^{\circ}$ by Hübner (2014), opposite tendencies can be seen. Accordingly, the influence of the lead on the withdrawal capacity remains unclear.

In a study by Hoelz et al. (2020), it was determined that the withdrawal capacity is influenced by different failure mechanisms. The failure mechanisms in the thread contact depend on the orientation of the wood fiber to the screw thread and thus has to be considered as disturbance variable. An experimental setup was presented by Hoelz et al. (2021c) which allows the investigation of the thread parameter influences in specific orientations to the wood fiber. Instead of wood screws, ripped bars with straight flanks were used. These so-called threaded test objects are similar to those used by Adachi et al. (2010). With this setup, the influence of the lead and the thread angle on the withdrawal capacity was investigated by Hoelz et al. (2021c) for a tangential screw-in direction in spruce. The lead was investigated in the range from 3.04 to $6.08 \mathrm{~mm}$ on five factor levels with the lead angle dependent according to Eq. (1) for an outer diameter of $8 \mathrm{~mm}$. The thread angle was varied on the levels $35^{\circ}, 40^{\circ}$, and $45^{\circ}$. Statistical analysis was performed using a multifactor analysis of variance. An influence of the lead could be shown. A smaller lead leads to a higher withdrawal capacity. Different explanations were presented to explain this influence with theoretical models. For this purpose, the model of bonding mechanisms according to Ayoubi und Trautz (2015) and the model of compression cones-tension rings by Ayoubi (2014) were used. Hoelz et al. (2021c) stated that the influence of the lead and lead angle must be studied independently to test the presented explanations. No influence could be shown for the thread angle. However, they suspected an influence and therefore suggested to investigate the thread angle in a wider range of values. Hoelz et al. (2021a) also suspect an influence of the thread angle on the withdrawal capacity and describe by means of a theoretical model that higher withdrawal capacities can be achieved for a smaller thread angle.

\subsection{Objective}

For optimization of wood screw threads, it is necessary to know which thread parameters influence the withdrawal capacity and how they influence it. So far, only the influence of the outer diameter and the lead is known. The influence of further parameters is only assumed. Gaunt (1997) assumes a positive effect of a large ratio between thread height and root depth on the withdrawal capacity. The root depth can also be described in terms of the thread angle due to the fundamental triangle of the ridge. For the thread angle, an influence is also assumed by Hoelz et al. (2021c) and by Hoelz et al. (2021a). The influence of the lead with a dependent lead angle according to Eq. (1) on the withdrawal capacity is known (Hoelz et al. 2021c). However, this was only determined for the interdependent parameters and not individually for the parameters flank distance and lead angle.

The objective of this paper is to determine the influence of thread height, flank distance, lead angle, and thread angle on the withdrawal capacity.

\section{Materials and methods}

The experimental setup with threaded test objects by Hoelz et al. (2021c) will be used to achieve the objective. It is used because, on the one hand, thread parameters can be varied specifically and no sets of thread parameters of commercial wood screws have to be investigated. On the other hand, the investigation in defined orientations of the wood fiber to the screw thread is made possible, whereby the influencing variable wood fiber can be controlled.

In the following, the threaded test objects and test specimens used are presented and the experimental setup is discussed. 


\subsection{Threaded test objects and test specimens}

In this study, threaded test objects are used as seen in Fig. 2 on the left. These are flat ribbed bars with uncoiled screw threads. To avoid lateral forces, the thread flanks were arranged in opposite directions on the front and back. Only complete flanks across the width of the threaded test object were used. The upper part is used for the connection to the pull-out machine. To ensure good comparability to the study by Hoelz et al. (2021c), the dimensions of the threaded test objects were adopted as seen in Fig. 2. The investigated parameters are the thread height $a$, flank distance $P$, thread angle $\alpha$, and the lead angle $\varphi$. For the threaded test objects, the lead and the lead angle are not dependent on Eq. (1), hence the more unambiguous term flank distance will be used in the following instead of the term pitch. The dependent parameter $\lg l$ describes the effective thread length. The variations used are shown in Chapter 2.3. These test objects are made from $90 \mathrm{MnCrV} 8$ which have been hardened at $840{ }^{\circ} \mathrm{C}$ and tempered for $50 \mathrm{~min}$ at $420^{\circ} \mathrm{C}$.

Screwing of the threaded test objects is not possible due to the rectangular flat geometry. They were therefore inserted in two test specimen halves braced against each other as shown in Fig. 2 (see Hoelz et al. 2021c). The halves have a cross-sectional area of $100 \mathrm{~mm}$ by $100 \mathrm{~mm}$ and a depth of $50 \mathrm{~mm}$. For the width of the threaded test objects of $10 \mathrm{~mm}$, the dimensions thus correspond to the minimum width and thickness in the screw-in direction defined in EN 1382 (2016).

The threaded test objects are inserted in the milled grooves of the halves which will be pressed together. The grooves each have a length of $53 \mathrm{~mm}$, a width of $11 \mathrm{~mm}$, and a depth of $2.5 \mathrm{~mm}$. The groove depth of both halves of $5 \mathrm{~mm}$ was hence slightly less than the depth of the threaded test objects of $5.04 \mathrm{~mm}$. This can be compared to pre-drilling with a diameter smaller than the inner diameter of the screws, which according to Brandner et al. (2019) has no influence on the withdrawal capacity.

Spruce (Picea abies) was used for the test specimens. Solid structural timber with a strength class of C24 according to EN 338 (2016) and grading characteristics according to DIN 4074-1 (2012) was used. The humidity was $15 \%$. The timber was screened so that only clear wood without knotholes, resin pockets, or fissures was used.

\subsection{Experimental setup}

The threaded test objects were inserted in a tangential direction to the wood grain. Due to the flat threaded test objects, the thread can be positioned in different planes to the wood fiber with unchanged screw-in direction. Therefore, the wood fiber planes RT and TL to the thread were investigated. These planes are shown in Fig. 3. The test specimen halves with inserted threaded test object are braced. In a similar test setup with wood screws, Hoelz et al. (2020) determined that bracing leads to comparable failure behavior to that of screwed-in screws in solid timber. A pre-tensioning force of $3.2 \mathrm{kN}$ is applied via two metal plates and helical compression springs (Sodemann Industrifjedre A/S, product: R205408, $94.2 \mathrm{~N} / \mathrm{mm}$, Hinnerup, Denmark). At this pre-load, gap-free contact of the test specimen halves over the entire surface and complete insertion of the thread in the wood is achieved. In individual cases in which no gap-free contact was achieved, the force was increased and then, the springs were unloaded to the nominal force. The experimental setup according to Hoelz et al. (2021c) is shown on the right in Fig. 3.
Fig. 2 On the left, threaded test objects with the factors flank distance $P$, thread height $a$, thread angle $\alpha$, and lead angle $\varphi$. On the right, test specimen halves. The dimensions are comparable to those found in Hoelz et al. (2021c)
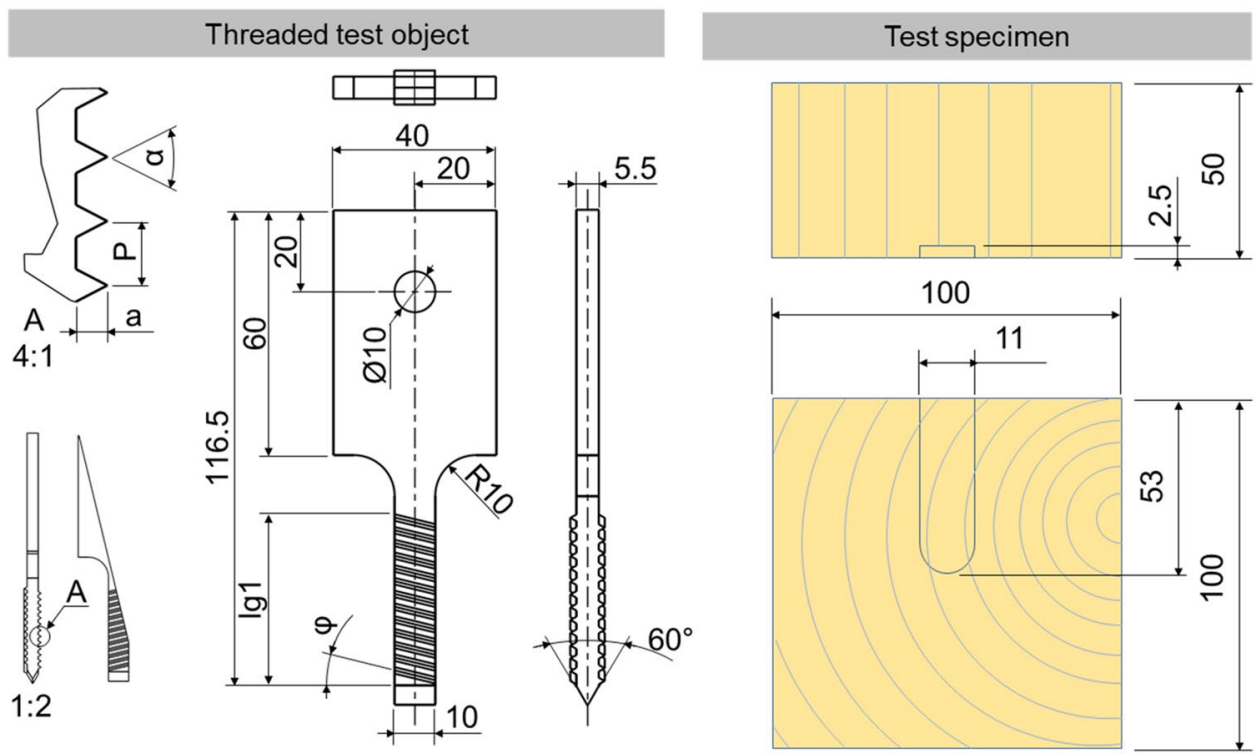
Fig. 3 On the left, a sectional view of the test specimen in the wood fiber planes RT and TL (Hoelz et al. 2021c) and on the right, the experimental setup with the inserted and braced threaded test objects in the test specimen

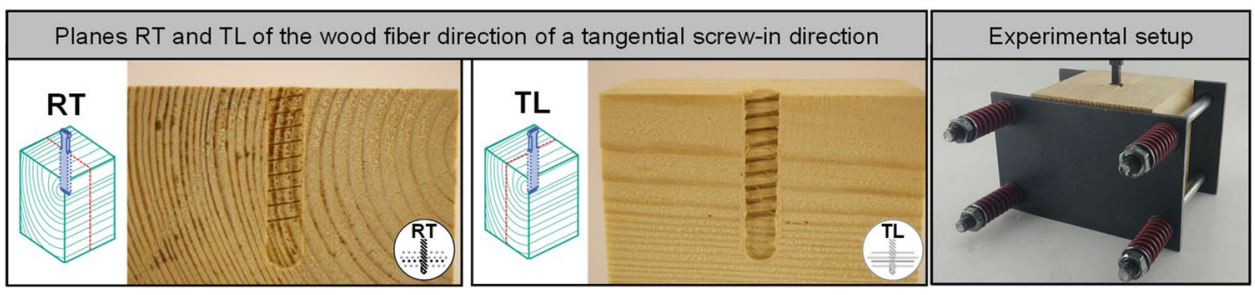

The pull-out tests were performed based on EN 1382 (2016) using a universal testing machine (TesT GmbH, product: Model 112, Erkrath, Deutschland). The pull-out tests are carried out with a uniform speed while measuring the force and displacement continuously. The maximum measured force corresponds to the withdrawal capacity. A bracket was used to support the experimental set-up against the pull-out machine. To comply with the minimum distances to the fastener defined in EN 1382 (2016), the distance of the bracket was $90 \mathrm{~mm}$ to the width and $70 \mathrm{~mm}$ to the depth of the threaded test objects.

\subsection{Study design: parameters and factor levels}

For this study, the factors flank distance $P$, lead angle $\varphi$, thread angle $\alpha$, and thread height $a$ are varied on two levels as seen in Table 1 below. This leads to a total of 16 threaded test objects (GP_A to GP_P). The flank distance was examined with $3.04 \mathrm{~mm}$ and $6.08 \mathrm{~mm}$, the lead angle with $6.8^{\circ}$ and $13.6^{\circ}$, the thread angle with $30^{\circ}$ and $55^{\circ}$, and the thread height with $1 \mathrm{~mm}$ and $1.48 \mathrm{~mm}$. The values of the factors are in a range that is practical for wood screws. Furthermore, comparability with the study by Hoelz et al. (2021c) was considered. The levels were set so that the thread length $l g l$ is as constant as possible. In a pilot evaluation, no trend of withdrawal capacities related to the thread length can be seen (Hoelz et al. 2022).

A full factorial experimental design with randomized order was used. Despite the care taken in the selection of the timber, it was assumed that the wood properties vary from beam to beam. However, these properties cannot be set in a targeted manner in the tests. Blocking was used to consider the variation in wood properties between pieces of timber beams. Blocking is a procedure in statistics to reduce the influence of known but uncontrollable factors in the evaluation. For blocking, the study was divided into blocks of 12 tests. Each piece of timber beam corresponds to one block of tests. Therefore, the length of the timber beams was selected to fit 12 tests. Due to the natural structure of the timber beams and corresponding wood defects, this length could not always be met. In the test evaluation, the blocks were considered as factor levels of the nominally scaled factor
Table 1 Selected factor levels, dependent thread length $\lg 1$, and number of experiments for wood fiber planes RT and TL of the threaded test objects GP_A to GP_P

\begin{tabular}{|c|c|c|c|c|c|c|c|}
\hline \multirow[t]{2}{*}{$\begin{array}{l}\text { Threaded test } \\
\text { object }\end{array}$} & \multicolumn{4}{|c|}{ Factors and factor levels } & \multirow{2}{*}{$\begin{array}{l}\text { Dependent parameter } \\
\text { lg1 in } \mathrm{mm}\end{array}$} & \multicolumn{2}{|c|}{$\begin{array}{l}\text { Number of } \\
\text { tests N }\end{array}$} \\
\hline & $P$ in $\mathrm{mm}$ & $\varphi$ in $^{\circ}$ & $\alpha$ in $^{\circ}$ & $a$ in $\mathrm{mm}$ & & RT & $\mathrm{TL}$ \\
\hline GP_A & 3.04 & 6.8 & 30 & 1 & 38.471 & 15 & 19 \\
\hline GP_B & 3.04 & 6.8 & 30 & 1.48 & 38.730 & 16 & 19 \\
\hline GP_C & 3.04 & 6.8 & 55 & 1 & 38.979 & 15 & 17 \\
\hline GP_D & 3.04 & 6.8 & 55 & 1.48 & 39.483 & 15 & 18 \\
\hline GP_E & 3.04 & 13.6 & 30 & 1 & 40.503 & 15 & 17 \\
\hline GP_F & 3.04 & 13.6 & 30 & 1.48 & 40.768 & 15 & 15 \\
\hline GP_G & 3.04 & 13.6 & 55 & 1 & 41.023 & 16 & 18 \\
\hline GP_H & 3.04 & 13.6 & 55 & 1.48 & 41.537 & 15 & 19 \\
\hline GP_I & 6.08 & 6.8 & 30 & 1 & 38.471 & 15 & 17 \\
\hline GP_J & 6.08 & 6.8 & 30 & 1.48 & 38.730 & 15 & 16 \\
\hline GP_K & 6.08 & 6.8 & 55 & 1 & 38.979 & 15 & 18 \\
\hline GK_L & 6.08 & 6.8 & 55 & 1.48 & 39.483 & 15 & 20 \\
\hline GP_M & 6.08 & 13.6 & 30 & 1 & 40.503 & 15 & 19 \\
\hline GP_N & 6.08 & 13.6 & 30 & 1.48 & 40.768 & 15 & 17 \\
\hline GP_O & 6.08 & 13.6 & 55 & 1 & 41.023 & 15 & 18 \\
\hline GP_P & 6.08 & 13.6 & 55 & 1.48 & 41.537 & 15 & 19 \\
\hline Total N & & & & & & 242 & 286 \\
\hline
\end{tabular}


piece of timber beam. Thus, the factor piece of timber beam describes different pieces of timber beams, which can vary in wood properties.

Multifactorial analyses of variance (ANOVA) were performed to determine the influence of the factors on the withdrawal capacity. An ANOVA was carried out for each plane RT and TL to the wood fiber. A unified statistical model with the same thread parameters and their interactions was chosen for both planes. This model was developed based on the significant thread parameters and interactions of the individual models of the planes. A unified model is advantageous for use in thread design. For the geometry of a wood screw thread, it is not possible to distinguish between both planes, but the thread parameters must be defined together for both planes to the wood fiber.

In the fiber plane RT, 242 tests were performed and 286 for the TL plane. Table 1 shows the test repetitions for the threaded test objects. At least 15 tests were carried out per threaded test object and per fiber plane. Only tests that did not show any complications were considered. The analysis was performed with SPSS Statistics Version 26.0.0.0.

For use of an ANOVA, the normal distribution of the dependent variables must be shown with the Kolmogorov-Smirnov test or the Shapiro-Wilk test. To test this normal distribution $\left(\alpha_{\mathrm{SL}}=0.05\right)$, the factor groups corresponding to the threaded test objects are examined with the Kolmogorov-Smirnov test. In both fiber planes RT and TL, all threaded test objects show a significance greater than $p>0.05$. Exceptions are the object GP_D with $p=0.024$ and GP_I with $p=0.024$ in plane RT. However, these can show significances greater than $p>0.05$ in a Shapiro-Wilk test. Therefore, a normal distribution can be assumed for all factor groups. The homogeneity of the variances is another requirement for using an ANOVA. This can be tested with a Levene's test $\left(\alpha_{\mathrm{SL}}=0.05\right)$. The Levene's test is neither significant for the RT plane $(\mathrm{F}(215,26)=1.231 ; p=0.271)$ nor for the TL plane $(\mathrm{F}(201,84)=1.167 ; p=0.211)$, so that variance homogeneity can be assumed. The conditions for applying an ANOVA are thus fulfilled for both investigations in the planes RT and TL. The analysis of the normal distribution, Levene's test, and the following results are available in the repository: (Hoelz et al. 2022).

\section{Results and discussion}

\subsection{Results}

The unified model of ANOVA uses the factors flank distance, thread angle, thread height, lead angle, piece of timber beam, and the interactions flank distance*lead angle, flank distance*thread height, flank distance*thread angle, thread angle*thread height, and thread angle*lead angle. For the RT plane, the overall model is significant $\left(\mathrm{F}(31,210)=16.78 ; p<0.001 ;\right.$ adjusted $\left.R^{2}=0.670 ; N=242\right)$. Significant effects on the withdrawal capacity can be shown for all main effects and all interactions of the unified model. Significant factors are flank distance $(\mathrm{F}(1,210)=48.151$; $p<0.001)$, thread angle $(\mathrm{F}(1,210)=10.436 ; p=0.001)$, thread height $(\mathrm{F}(1,210)=120.697 ; p<0.001)$, lead angle $(\mathrm{F}(1,210)=11.777 ; p=0.001)$, and piece of timber beam $(\mathrm{F}(22,210)=12.223 ; p<0.001)$. Furthermore, there are significant interactions between flank distance and lead angle $(\mathrm{F}(1,210)=4.259 ; p=0.04)$, flank distance and thread height $(\mathrm{F}(1,210)=46.524 ; p<0.001)$, flank distance and thread angle $(\mathrm{F}(1,210)=3.956 ; p=0.048)$, thread angle and thread height $(\mathrm{F}(1,210)=8.468 ; p=0.004)$, and thread angle and lead angle $(\mathrm{F}(1,210)=5.139 ; p=0.024)$. The result is shown in Table 2.

The result for TL plane is shown in Table 3. The overall model is significant $(\mathrm{F}(25,260)=20.95$; $p<0.001$; adjusted $\left.R^{2}=0.636 ; N=286\right)$. The factors flank distance $(\mathrm{F}(1,260)=96.206 ; p<0.001)$, thread angle $(\mathrm{F}(1,260)=9.776 ; p=0.002)$, thread height $(\mathrm{F}(1,260)=183.446 ; p<0.001)$, and piece of timber beam $(\mathrm{F}(16,260)=14.512 ; p<0.001)$ have significant influences on withdrawal capacity. A significant interaction can be shown between flank distance and thread angle $(\mathrm{F}(1,260)=4.718 ; p=0.031)$. No effects could be shown for the lead angle as well as the interactions flank distance and lead angle, flank distance and thread height, thread angle and thread height, and thread angle and lead angle.

The effect sizes of significant factors are determined according to Cohen $(1988,1992)$ and divided into small, medium, and large. Only small and large effects are determined. The partial eta2 from Tables 2, 3 are used for the calculation. Effect sizes for the factors are shown in Table 4 for both planes RT and TL. For main effects, the effect sizes

Table 2 Result of the ANOVA for the RT plane to wood fiber

\begin{tabular}{lrll}
\hline Dependent variable: withdrawal capacity & & \\
\hline Source & \multicolumn{1}{l}{ F } & $p$-value & Partial eta $^{2}$ \\
\hline Corrected model & 16.782 & $<0.001$ & 0.712 \\
Flank distance & 48.151 & $<0.001$ & 0.187 \\
Thread angle & 10.436 & 0.001 & 0.047 \\
Thread height & 120.697 & $<0.001$ & 0.365 \\
Lead angle & 11.777 & 0.001 & 0.053 \\
Piece of timber beam & 12.223 & $<0.001$ & 0.561 \\
Flank distance*lead angle & 4.259 & 0.040 & 0.020 \\
Flank distance*thread height & 46.524 & $<0.001$ & 0.181 \\
Flank distance*thread angle & 3.956 & 0.048 & 0.018 \\
Thread angle*thread height & 8.468 & 0.004 & 0.039 \\
Thread angle*lead angle & 5.139 & 0.024 & 0.024 \\
\hline
\end{tabular}

$R^{2}=0.712\left(\right.$ adjusted $\left.R^{2}=0.670\right)$ 
Table 3 Result of the ANOVA for the TL plane to wood fiber

\begin{tabular}{lrll}
\hline Dependent variable: withdrawal capacity & & \\
\hline Source & \multicolumn{1}{l}{ F } & $p$-value & Partial eta $^{2}$ \\
\hline Corrected model & 20.946 & $<0.001$ & 0.668 \\
Flank distance & 96.206 & $<0.001$ & 0.270 \\
Thread angle & 9.776 & 0.002 & 0.036 \\
Thread height & 183.446 & $<0.001$ & 0.414 \\
Lead angle & 3.354 & 0.068 & - \\
Piece of timber beam & 14.512 & $<0.001$ & 0.472 \\
Flank distance*lead angle & 0.888 & 0.347 & - \\
Flank distance*thread height & 1.896 & 0.170 & - \\
Flank distance*thread angle & 4.718 & 0.031 & 0.018 \\
Thread angle*thread height & 1.819 & 0.179 & - \\
Thread angle*lead angle & 1.898 & 0.169 & - \\
\hline
\end{tabular}

$R^{2}=0.668\left(\right.$ adjusted $\left.R^{2}=0.636\right)$

are in the upper half of the table, and for the interactions in the lower half.

In RT plane effect sizes are found to be large for flank distance $(f=0.479)$, thread height $(f=0.758)$, piece of timber beam $(f=1.132)$, and the interaction flank distance and thread height $(f=470)$. The effects thread angle $(f=0.222)$ and lead angle $(f=0.237)$ are rated as small effects. Furthermore, the interactions flank distance and lead angle $(f=0.142)$, flank distance and thread angle $(f=0.137)$, thread height and thread angle $(f=0.201)$, as well as thread angle and lead angle $(f=0.156)$ show small effect sizes. For the TL plane, the main effects that can be evaluated as being strong are flank distance $(f=0.608)$, thread height $(f=0.839)$, and piece of timber beam $(f=0.945)$. The thread angle $(f=0.193)$ and the interaction flank distance and thread angle $(f=0.134)$ have small effect sizes.

Table 5 shows the withdrawal capacities for the planes RT and TL. The number of tests (N), minima (Min), maxima

Table 4 Effect sizes of the main effects and interactions for the two planes RT and TL

\begin{tabular}{|c|c|c|c|c|}
\hline \multirow[t]{2}{*}{ Effect sizes } & \multicolumn{2}{|l|}{ RT } & \multicolumn{2}{|l|}{ TL } \\
\hline & Large & Small & Large & Small \\
\hline Flank distance & 0.479 & & 0.608 & \\
\hline Thread angle & & 0.222 & & 0.193 \\
\hline Thread height & 0.758 & & 0.839 & \\
\hline Lead angle & & 0.237 & & \\
\hline Piece of timber beam & 1.132 & & 0.945 & \\
\hline Flank distance*lead angle & & 0.142 & & \\
\hline Flank distance*thread height & 0.470 & & & \\
\hline Flank distance*thread angle & & 0.137 & & 0.134 \\
\hline Thread height*thread angle & & 0.201 & & \\
\hline Thread angle*lead angle & & 0.156 & & \\
\hline
\end{tabular}

(Max), mean values, and standard deviations (SD) are given. In the TL plane, lower withdrawal capacities are achieved compared to the RT plane.

Because a unified statistical model was chosen for the two planes RT and TL, the determined effects can be shown in the same diagrams. In each case, the diagrams show the estimated marginal means of the withdrawal capacity for the effects of the two factor levels. The estimated marginal means represent the expected mean values of the factors based on the model, not the measured mean values. The error bars indicate the $95 \%$ confidence interval. In the diagrams, the means are given, the other values are in the repository: (Hoelz et al. 2022).

Figure 4 shows the main effects. The round markers represent the $\mathrm{RT}$ plane, whereas triangular markers represent the TL plane. Figure 4 a shows the influence of thread height on the estimated marginal mean of the withdrawal capacity. The larger thread height of $1.48 \mathrm{~mm}$ has a higher withdrawal capacity in both planes. In the RT plane, the larger thread height results in a $14 \%$ increase and in the TL plane, a $19 \%$ increase in the estimated marginal mean of the withdrawal capacity. In Fig. 4b, the influence of the flank distance is shown. In both planes, the withdrawal capacity decreases for a larger flank distance. In the RT plane, the flank distance causes an increase in the estimated marginal mean of the withdrawal capacity of $9 \%$, and in TL of $14 \%$. The relationship between thread angle and withdrawal capacity is shown in Fig. 4c. The more acute thread angle shows a higher withdrawal capacity in both planes $(+4 \%)$. Figure $4 d$ shows the weak influence of the lead angle in the TL plane. This effect could not be demonstrated in the ANOVA. In the RT plane, the $13.6^{\circ}$ lead angle shows the higher withdrawal capacity $(+4 \%)$.

In Fig. 5, the interactions between thread parameters on the estimated marginal means of the withdrawal capacity are presented. In Fig. 5e, the interaction of the flank distance with the thread height is shown. The interaction is clearly visible in the RT plane. At a thread height of $1.48 \mathrm{~mm}$, the flank distance has no influence on the withdrawal capacity. At the thread height of $1.0 \mathrm{~mm}$, a positive influence of the smaller flank distance on the withdrawal capacity can be seen. In the TL plane, no interaction can be seen and could not be shown statistically either. The interaction between flank distance

Table 5 Withdrawal capacities for the planes RT and TL

\begin{tabular}{lllrll}
\hline $\begin{array}{l}\text { Wood } \\
\text { fiber } \\
\text { plane }\end{array}$ & $\mathrm{N}$ & Min in kN & Max in kN & Mean in kN & SD in kN \\
\hline RT & 242 & 4.107 & 10.140 & 7.480 & 1.174 \\
TL & 286 & 2.929 & 7.905 & 5.440 & 0.981 \\
\hline
\end{tabular}



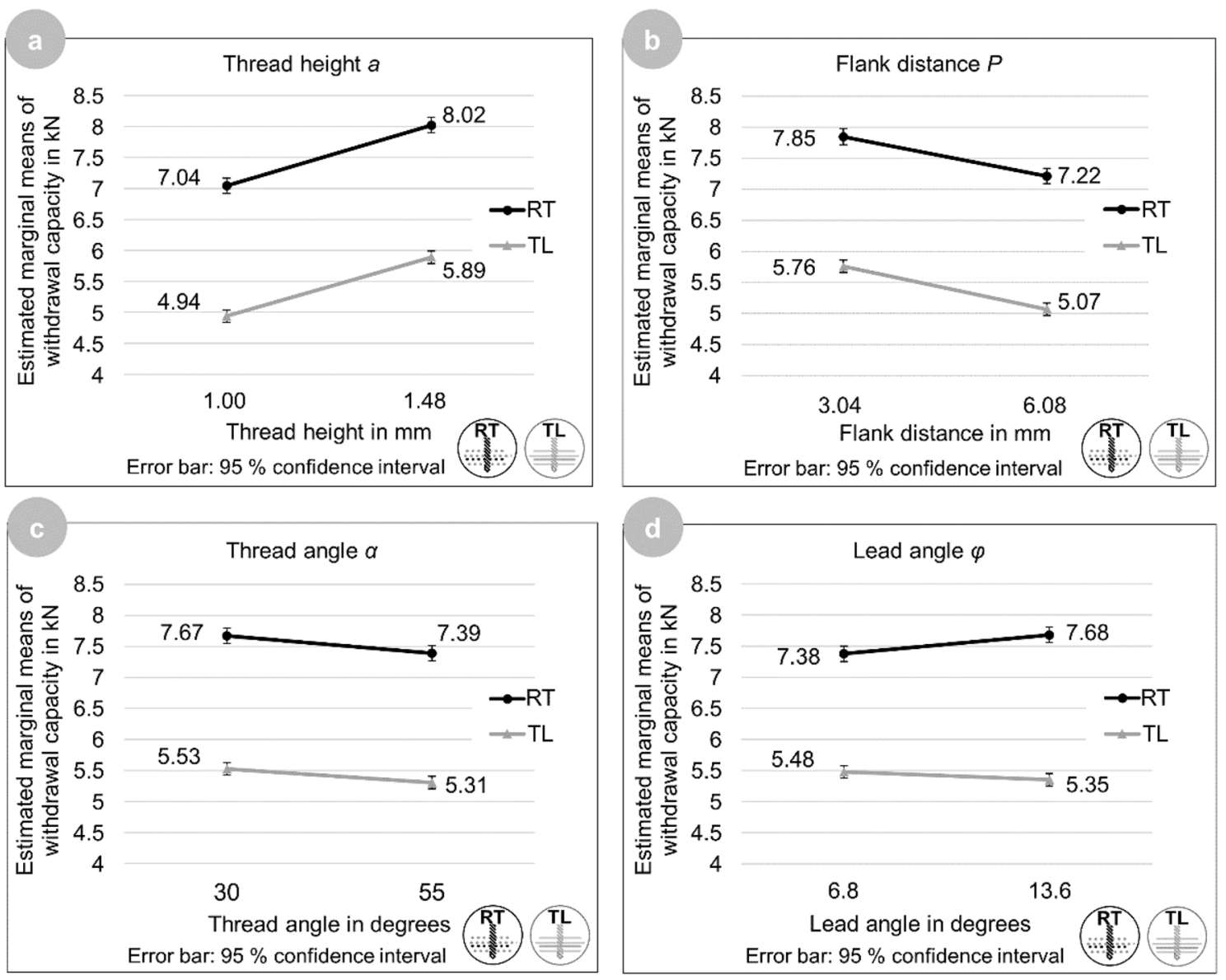

Fig. 4 Diagrams for the main effects. Influence $\mathbf{a}$ of the thread height and $\mathbf{b}$ of the flank distance on the estimated marginal means of the withdrawal capacity for both planes RT and TL. Influence $\mathbf{c}$ of the thread angle and $\mathbf{d}$ of the lead angle

and lead angle is shown in Fig. 5f. A smaller lead angle increases the influence of the flank distance in the RT plane. In the TL plane, no interaction of the parameters is visible and could not be shown statistically either.

The influence of the thread angle on the relationship between flank distance and withdrawal capacity is shown in Fig. 5g. A more acute thread angle increases the effect for a higher withdrawal capacity for both planes. However, for the flank distance of $6.08 \mathrm{~mm}$, the thread angle has no influence on the withdrawal capacity. The interaction of the thread height and the thread angle is shown in Fig. $5 \mathrm{~h}$. At the thread height of $1.48 \mathrm{~mm}$, the thread angle has nearly no influence on the withdrawal capacity. At the lower thread height, the smaller thread angle leads to a higher withdrawal capacity. However, in the TL plane, this influence could not be proven statistically.

Figure 5i shows the interaction between lead angle and thread angle regarding the withdrawal capacity. Statistically, this interaction could not be shown in the TL plane.

\subsection{Discussion}

The influences of the thread parameters on the withdrawal capacity were determined in different investigations for the two planes to the wood fiber RT and TL. In both analyses of variance, a comparable coefficient of determination (adjusted $R^{2}$ : RT 0.712 ; TL 0.668 ) with reasonable quality could be obtained.

The influence of flank distance, lead angle, thread angle, and thread height, as well as interactions of these parameters on the withdrawal capacity were shown. This was achieved by the threaded test objects and the independent variation of the thread parameters. In both planes, the main effects and interactions of the thread parameters are aligned or neutral to each other. This is good for the design to optimize the geometry of wood screws. The design of the wood screw thread must consider both planes due to the circumferential thread. Opposing effects of the thread parameters for the planes would mean a conflict for design. The effects determined can 

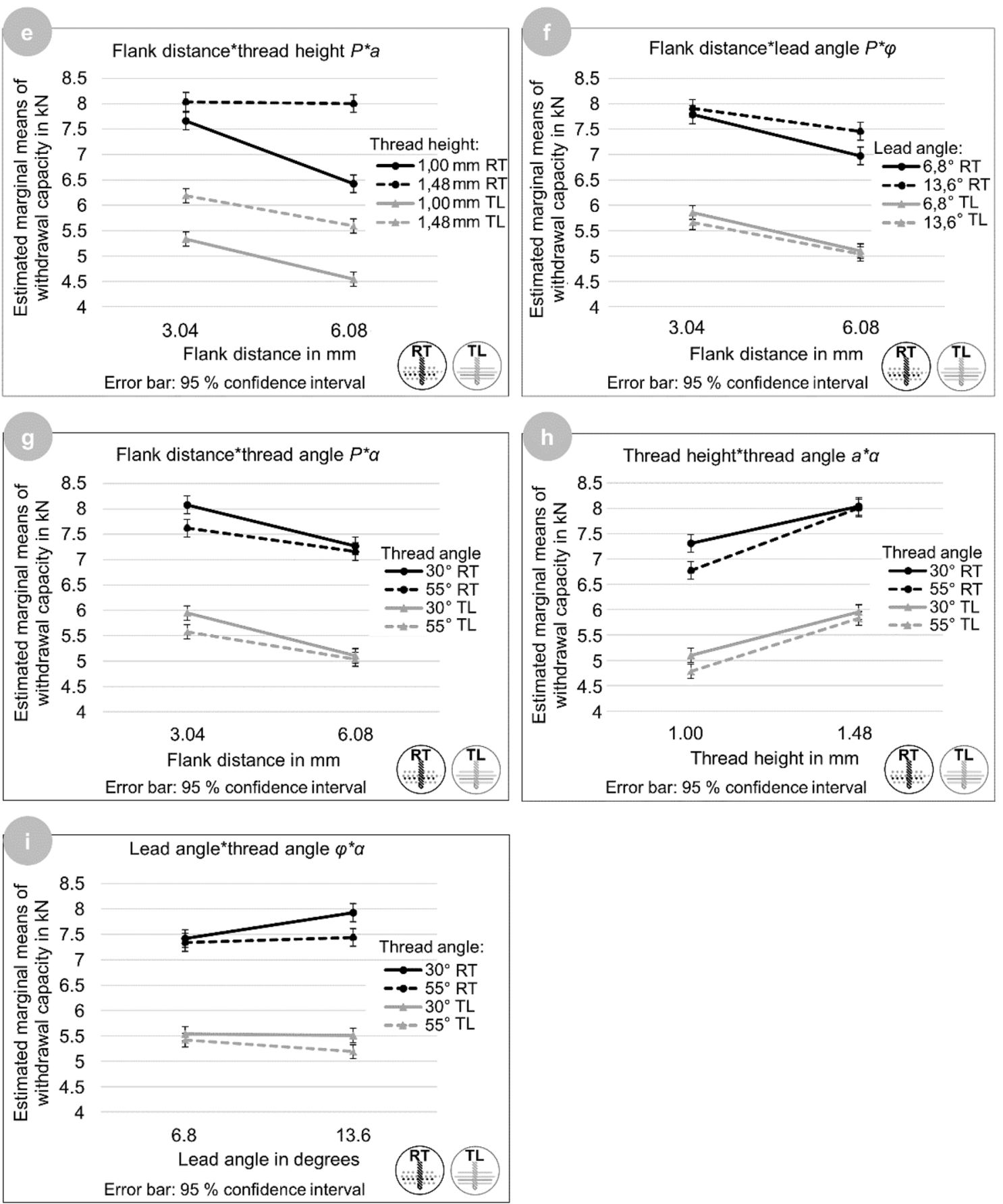

Fig. 5 Interactions of the thread parameters for both planes RT and TL. Relationships between the estimated marginal means of the withdrawal capacity and e flank distance*thread height, $\mathbf{f}$ flank distance*lead angle, $\mathbf{g}$ flank distance*thread angle, $\mathbf{h}$ thread height*thread angle, as well as i lead angle*thread angle

withdrawal capacities. In both studies, higher withdrawal capacities were determined for the RT plane. The mean values of the withdrawal capacities and the standard deviations are comparable across the studies for the RT and TL planes, respectively. This comparison shows the reliability of the experimental setup. 
As in Hoelz et al. (2021c), a limitation of the experimental setup results from the change in the absolute values of the withdrawal capacity. By bracing the test specimen halves, the absolute values of the withdrawal capacities change. The geometric dimensions of the threaded test objects also change the absolute values. Usually, the tested thread length is $8 d$ and the perimeter is $\pi d$. For transferability of the values to wood screws, the geometric dimensions of the threaded test objects should be aligned with these. However, to ensure comparability to Hoelz et al. (2021c), the same dimensions were chosen despite these limitations.

The influence of the thread angle on the withdrawal capacity could not be shown by Hoelz et al. (2021c) in the range between $35^{\circ}$ and $45^{\circ}$. The influence of this thread angle could now be proven in a wider range for $30^{\circ}$ and $55^{\circ}$. The interaction diagram of thread height and thread angle shows that at a thread height of $1.48 \mathrm{~mm}$, the thread angle has barely any influence on the withdrawal capacity. Hoelz et al. (2021c) investigated the influence of the thread angle at a thread height of $1.48 \mathrm{~mm}$, whereby they could show no influence.

Gaunt (1997) suspected an influence of the relationship between thread height and root depth on the withdrawal capacity. The root depth correlates with the thread angle. As the parameters thread height and thread angle were investigated, this assumption can be tested. Gaunt (1997) investigated the assumption with thread heights in the range of 3-9 $\mathrm{mm}$. This resulted in ratios of thread height and root depth in the range between 1 and 2 . The ratio of the examined threaded test objects with a thread height of $1 \mathrm{~mm}$ and a thread angle of $55^{\circ}$ is 0.55 . With a thread height of $1.48 \mathrm{~mm}$ and a thread angle of $30^{\circ}$, a ratio of 0.5 is obtained. A positive influence of a smaller ratio can be shown in the interaction diagram between thread height and thread angle. Despite the differences in the ratios, the assumption by Gaunt (1997) can be supported.

To explain the effects of the flank distance and lead angle, different models were presented by Hoelz et al. (2021c). For this, the model of bonding mechanisms by Ayoubi und Trautz (2015) and the model of compression cone-tension ring by Ayoubi (2014) were used. Thus, Hoelz et al. (2021c) described that a change in the lead angle leads to changed proportions of the bonding mechanism, namely shear bond and friction bond. Therefore, they predicted that at constant flank distance, a smaller lead angle leads to a higher withdrawal capacity. However, the results show that in the RT plane, a larger lead angle leads to a higher withdrawal capacity in this plane. Therefore, the explanation with this model cannot be confirmed.

To explain the influence of the flank distance, Hoelz et al. (2021c) assume that the withdrawal capacity depends on the size of the shear area. A smaller flank distance results in a higher number of flanks for the same thread length. Due to the higher number of flanks, a larger volume of the wood matrix fails at a given screw displacement. The remaining smaller shear area causes the wood screw connection to fail earlier. According to this model, a larger flank distance leads to a higher withdrawal capacity. Based on the experimental results by Hoelz et al. (2021c), they restricted that this model can only be valid if the effect of the lead angle is smaller than the effect of the flank distance. The results show that the flank distance has a large effect size and the lead angle has a small effect size. Therefore, the conditions of the model are not satisfied.

Hoelz et al. (2021c) presented another model to explain the influence of the flank distance. Based on compression cones, the model assumes that the wood matrix near the flank will fail first, compromising the withdrawal capacity. Due to a smaller flank distance, the following higher number of flanks results in a higher number of load transmission points into the wood. As a result, the mechanical stress at the individual load transmission points is lower. Therefore, they predicted that a smaller flank distance will lead to a higher withdrawal capacity. The results show that the smaller flank distance of $3.04 \mathrm{~mm}$ leads to a higher withdrawal capacity, which supports this model.

Hoelz et al. (2021a) also explain the influence of the thread angle with compression cones. They describe that the angle of the compression cone is formed in extension to the flank. Thus, they assume that a smaller thread angle leads to larger compression cones and therefore to higher withdrawal capacities. The experimental data supports this model.

In both planes, the main effects thread height, flank distance, and thread angle show aligned, approximately parallel trends. This suggests that the bonding mechanisms and failure processes underlying the main effects are similar for both planes. Therefore, the effects can be explained by the same models. For the effects of the flank distance and the thread angle, confirmations could be found for the models based on compression cones. The influences of the lead angle and thread height cannot yet be explained. Furthermore, more interactions of the thread parameters were shown in the RT plane than in the TL. One possibility is that in the RT plane, additional failure processes are involved, through which the interactions between thread parameters and withdrawal capacity arise. These failure mechanisms are not described by the models so far. One reason for this is that the models only represent the bond between the screw and the wood in a very simplified way. By including the material properties of wood and the failure processes as described in the model by Hübner (2014), the explanations of the effects by models could be significantly improved. This should also be supported by experimental studies such as Hoelz et al. (2021b) to determine how thread parameters affect failure in thread contact. 


\section{Conclusion and outlook}

Influences of the thread parameters thread height, thread angle, lead angle, flank distance, and their interactions on the withdrawal capacity in spruce were investigated in this study. The thread height was investigated with the values $1 \mathrm{~mm}$ and $1.48 \mathrm{~mm}$, the flank distance with $3.04 \mathrm{~mm}$ and $6.08 \mathrm{~mm}$, the thread angle with $30^{\circ}$ and $55^{\circ}$, and the lead angle with $6.8^{\circ}$ and $13.6^{\circ}$. Significant main effects are thread height, flank distance, and thread angle. A larger thread height, a smaller thread pitch, and a more acute thread angle increases the withdrawal capacity. Regarding practical application, the determined effects could be used for optimization of the thread geometry of wood screws with higher withdrawal capacities. Calculation models can also be improved. The experimental results are consistent with the compression cone models explaining the influence of flank distance and thread angle. To explain further influences and interactions, the models should be improved by considering the material properties of wood and the failure processes.

Funding Open Access funding enabled and organized by Projekt DEAL. No funding was received to assist with the preparation of this manuscript.

Data availability The analysis of the experimental data with multifactorial analyses of variance is provided in the following repository: (Hoelz et al. 2022).

Code availability Not applicable.

\section{Declarations}

Conflict of interest The authors declare that they have no conflict of interest.

Open Access This article is licensed under a Creative Commons Attribution 4.0 International License, which permits use, sharing, adaptation, distribution and reproduction in any medium or format, as long as you give appropriate credit to the original author(s) and the source, provide a link to the Creative Commons licence, and indicate if changes were made. The images or other third party material in this article are included in the article's Creative Commons licence, unless indicated otherwise in a credit line to the material. If material is not included in the article's Creative Commons licence and your intended use is not permitted by statutory regulation or exceeds the permitted use, you will need to obtain permission directly from the copyright holder. To view a copy of this licence, visit http://creativecommons.org/licenses/by/4.0/.

\section{References}

Adachi K, Takehira K, Soma T, Inoue M (2010) Study of mechanical properties of wooden bolt-nut connector I: effect of size and shape of thread on withdrawal strength. J Wood Sci 56(6):502-506. https://doi.org/10.1007/s10086-010-1120-7
Ayoubi M (2014) Bond behaviour of self-tapping screws with continuous threads and long embedment length being used as reinforcement in glue-laminated timber elements. Dissertation, Technische Hochschule Aachen

Ayoubi M, Trautz M (2015) Bond behaviour of self-tapping screws being used as reinforcement in glue-laminated timber elements. Part 1: Experimental investigations on self-tapping screws with continuous threads and long embedment length being used as reinforcement in glue-laminated timber elements. Bautechnik 92(11):790-799. https://doi.org/10.1002/bate.201400098

Ballerini M (2012) Experimental investigation on parallel-to-grain wood-to-wood joints with self-tapping screws. In: Quenneville $\mathrm{P}$ (ed.). Proceedings of world conference on timber engineering 2012 (WCTE), vol. 4. Curran, Red Hook, NY, pp. 173-182

Blaß HJ, Bejtka I, Uibel T (2006) Tragfähigkeit von Verbindungen mit selbstbohrenden Holzschrauben mit Vollgewinde (Load carrying capacity of connections with fully threaded self-tapping wood screws) (In German), vol 4. Universitätsverlag Karlsruhe, Karlsruhe. https://doi.org/10.5445/KSP/1000004810

Brandner R, Ringhofer A, Reichinger T (2019) Performance of axially-loaded self-tapping screws in hardwood: Properties and design. Eng Struct 188:677-699. https://doi.org/10.1016/j. engstruct.2019.03.018

Cohen J (1988) Statistical power analysis for the behavioral sciences, 2nd edn. Erlbaum, Hillsdale. https://doi.org/10.4324/ 9780203771587

Cohen J (1992) A power primer. Psychol Bull 112(1):155-159. https://doi.org/10.1037/0033-2909.112.1.155

DIN 4074-1 (2012) Strength grading of wood-Part 1: coniferous sawn timber. Beuth, Berlin

EN 1382 (2016) Timber structures-Test methods-Withdrawal capacity of timber fasteners. Beuth, Berlin

EN 14592 (2012) Timber structures-dowel-type fasteners-requirements. Beuth, Berlin

EN 338 (2016) Structural timber-strength classes. Beuth, Berlin

Franke B, Quenneville P (2011) Numerical modeling of the failure behavior of dowel connections in wood. J Eng Mech 137(3):186-195. https://doi.org/10.1061/(ASCE)EM.19437889.0000217

Frese M, Fellmoser P, Blaß HJ (2010) Models for the calculation of the withdrawal capacity of self-tapping screws. Eur J Wood Prod 68(4):373-384. https://doi.org/10.1007/s00107-009-0378-1

Gaunt D (1997) The effect of thread geometry on screw withdrawal strength. N Z Timber Des J 6(3):12-20

Hoelz K, Grauberger P, Matthiesen S (2020) Investigation of failure behavior in the thread contact of wood screws during the pullout process. J Struct Eng 146(10):1-13. https://doi.org/10.1061/ (ASCE)ST.1943-541X.0002784

Hoelz K, Ayoubi M, Gwosch T, Matthiesen S (2021a) Models for the bond behavior of wood screws for design. Bautechnik 98(2):8694. https://doi.org/10.1002/bate.202100003

Hoelz K, Dörner P-T, Matthiesen S (2021b) Analysis of failure using image recognition for the design of wood screws. Konstruktion 73(01-02):64-69. https://doi.org/10.37544/ 0720-5953-2021-01-02-64

Hoelz K, Kleinhans L, Matthiesen S (2021c) Wood screw design: influence of thread parameters on the withdrawal capacity. Eur J Wood Prod 79(4):773-784. https://doi.org/10.1007/s00107-021-01668-4

Hoelz K, Hohlweg J, Matthiesen S (2022) Research data on the influence of thread parameters on the withdrawal capacity of wood screws. Karlsruhe Institute of Technology (KIT), Karlsruhe. https://doi.org/10.5445/IR/1000141497

Höfferl B, Hollinsky K, Passer A, Teibinger M, Woschitz R, Pech A et al (2016) 2. Holztechnologie-baustoffe und produkte (wood technology-building materials and products) (In German). In: Pech A (ed) Holz im hochbau. Theorie und praxis (wood 
in building construction: theory and practice) (In German). Birkhäuser, Berlin, pp 19-68. https://doi.org/10.1515/9783035607 529-004

Hoffmeyer P (2016) Holzanatomie (wood anatomy) (In German). In: Blaß HJ, Sandhaas C (eds) Ingenieurholzbau—grundlagen der bemessung (structural timber-design rules) (In German). KIT Scientific Publishing, Karlsruhe, pp 21-36. https://doi.org/10. 5445/KSP/1000054023

Hübner U (2014) Mechanische Kenngrößen von Buchen-, Eschen- und Robinienholz für lastabtragende Bauteile (Mechanical parameters of beech, ash and black locust wood for load-bearing components) (In German). Dissertation, TU Graz

ISO 5408 (2009) Screw threads-vocabulary. Beuth, Berlin

Pirnbacher G, Schickhofer G (2007) Comparison of screws-an empirical view. In: Pirnbacher G (ed) Verbindungstechnik im Ingenieurholzbau, vol 6. Verlag der Technischen Universität Graz, Graz, pp F1-F22

Ringhofer A, Brandner R, Flatscher G, Schickhofer G (2015a) Axially loaded screws in solid timber, glued laminated timber and cross laminated timber. Bautechnik 92(11):770-782. https://doi.org/10. 1002/bate. 201500075

Ringhofer A, Brandner R, Schickhofer G (2015b) A universal approach for withdrawal properties of self-tapping screws in solid timber and laminated timber products. In: Görlacher R (ed) Proceedings of INTER-international network on timber engineering research. Timber Scientific Publishing, Karlsruhe, pp 79-96

Sydor M (2019) Geometry of wood screws: a patent review. Eur J Wood Prod 77(1):93-103. https://doi.org/10.1007/s00107-018-1362-4

Sydor M, Zmyślony G, Pinkowski G, Szymański W (2016) The influence of pitch on the holding power of screws in scots pine wood. Annals of WULS-SGGW. For Wood Technol 96:151-156

Publisher's Note Springer Nature remains neutral with regard to jurisdictional claims in published maps and institutional affiliations. 